\title{
THE DEMOGRAPHICS OF A 15-YEAR DECLINE IN COVER OF THE CARIBBEAN REEF CORAL MONTASTRAEA ANNULARIS
}

\author{
Peter J. Edmunds ${ }^{1}$ and Robin Elahi
}

Department of Biology, California State University, 18111 Nordhoff Street, Northridge, California 91330-8303, USA

\begin{abstract}
On Caribbean reefs, a striking trend of the last 25 years has been the decline in cover of the framework-building coral Montastraea annularis, a species that has dominated reefs throughout the region for millennia. Clearly, such losses are important ecologically, but to evaluate their significance fully, they need to be placed in the context of the proximal causes and balanced against the potential for gains in cover through growth and recruitment. In this study, a population of M. annularis in St. John, U.S. Virgin Islands, was censused annually from 1988 to 2003 to quantify coral cover and construct a size-based demographic model. The model was developed to explore the mechanisms of change in coral cover and to ascertain likely trajectories for future population growth. Over the study period, the cover of $M$. annularis declined from $41 \%$ in 1988 , to $\sim 12 \%$ by 1999 (a $72 \%$ decline) but remained unchanged statistically for the last five years of the study. Between 1988 and 2003, colony abundances declined by $57 \%$ (from 47 colonies $/ \mathrm{m}^{2}$ to 20 colonies $/ \mathrm{m}^{2}$ ), and the losses were driven mostly by the death and fission of medium to large colonies (i.e., $\geq 151 \mathrm{~cm}^{2}$ ). By 2003 , the population had proportionally more small colonies $\left(70 \%\right.$ were $\left.\leq 50 \mathrm{~cm}^{2}\right)$ and fewer large colonies $\left(3 \%\right.$ were $\left.>250 \mathrm{~cm}^{2}\right)$ than in 1988 (60\% and $6 \%$, respectively), and the changes in population structure had accelerated $\geq 14 \%$ in terms of the rate of change in population size and the time necessary to attain equilibrium of colony size structure. Importantly, this analysis revealed an ongoing and imminent population decline coincident with the recent period of apparently stable coral cover. Fifty-year projections indicate the strong likelihood of extirpation of $M$. annularis at this particular site in St. John (in contrast to a continuation of constant low cover) and suggest that the 1988 population structure cannot be restored by recruitment. It is unlikely that the population decline will reverse until there is an amelioration of the conditions that kill individual colonies.
\end{abstract}

Key words: Caribbean; coral; demographics; marine protected area; Montastraea annularis; St. John; Scleractinia; U.S. Virgin Islands; Yawzi Point.

\section{INTRODUCTION}

The global, widespread ecological decline of coral reefs (Gardner et al. 2003, Pandolfi et al. 2003, Bellwood et al. 2004) provides one of the best-known examples of contemporary biome degradation (Woodruff 2001). Decreases in coral cover were recorded in some of the earliest quantitative analyses of coral reef communities (Stoddart 1969, Woodley et al. 1981), but by the end of the 20th century, the losses in some locations justified coining the term "phase change" to describe the switch from coral to macroalgal dominance (Done 1992, Knowlton 1992, 2004). Shortly before these events gained widespread attention, the first-known regionwide coral-bleaching episode occurred throughout the Caribbean in 1987 (Roberts 1987), and similar episodes since have become more frequent (Hoegh-Guldberg 1999, Berkelman et al. 2004). Although there is still much uncertainty concerning the fate of coral reefs (Knowlton 2001, Buddemeier et al. 2004), there is a

Manuscript received 20 July 2005; revised 1 June 2006; accepted 2 June 2006. Corresponding Editor: M. H. Carr.

${ }^{1}$ E-mail: peter.edmunds@csun.edu growing consensus that they will change rather than disappear entirely (Hughes et al. 2003), most likely through shifts in relative abundances of coral species (Hughes et al. 2003), with some even altering their ecological ranges (Precht and Aronson 2004).

The principal tool for describing changes in coral community structure is the analysis of percentage cover of benthic taxa, with the cover of live scleractinian coral serving as the bellwether of reef condition (Connell 1997, Bellwood et al. 2004). Typically, a decline of coral cover is interpreted as "bad," with an increase being "good" (Hughes and Tanner 2000, Gardner et al. 2003), but such inferences can be misleading because coral cover provides little information regarding the mechanistic basis of the changes (Hughes 1984, 1996, Babcock 1991) and can serve as an ambiguous indicator of trajectories of population and community dynamics. A good example of the limitations of cover as the metric of species abundance comes from Jamaica, where reefs have long served as the poster child of Caribbean reef decline (Hughes 1994, 1996, Aronson and Precht 2001a). In this location, analyses of community structure over 16 years, based on both coral cover and demographic approaches, led at times to dissimilar outcomes (Hughes 
and Tanner 2000). During 1986 and 1987, a downward trajectory of cover of the reef-building coral Montastraea annularis was contrary to the upward trajectory of changing population size (i.e., number of colonies) (Hughes and Tanner 2000). More importantly, Hughes and Tanner (2000) were able to use a demographic approach to evaluate several mechanisms as possible explanations for the changes in coral cover, in part by employing population projections (sensu Caswell 2001). Although demographic approaches have been used in several studies designed to investigate the causes and consequences of changes in coral cover (Hughes 1984, Hughes and Jackson 1985, Done 1987, 1988, Babcock 1991, Fong and Glynn 2000, Lirman and Miller 2003, Edmunds 2005, Smith et al. 2005), in general, the population biology of scleractinian corals still remains poorly known (Connell 1973, Bak and Meesters 1999).

In terms of assessing temporal trends in coral communities, the significance of changes in cover varies among species and their ecological roles. Changes in cover of primary frame-building corals (sensu Goreau 1959, Sheppard 1982) have a greater effect on coral community structure than changes in cover of secondary frame-building species. For example, the Caribbeanwide losses of the frame-building corals Acropora palmata and $A$. cervicornis due to white band disease in the 1980s (Gladfelter 1982, Aronson and Precht $2001 b$ ) has had a long and enduring effect on the ecology of reefs throughout the region (Aronson and Precht 2001b). Among Caribbean reef-building corals, Montastraea annularis provides a special case in terms of changes in coral cover because this species plays critical roles in reef construction and community ecology (Goreau 1959, Barnes 1973, Knowlton 1992) and has fulfilled these roles for millennia (Mesolella 1967, Jackson 1992). Moreover, the fossil record indicates that Caribbean corals that form large colonies, corals like $M$. annularis, have survived periods of adverse conditions better than species characterized by small colonies (Johnson et al. 1995). Together, these characteristics underscore the negative ecological consequences and temporal novelty of the ongoing declines in cover of M. annularis in Jamaica (Hughes 1994, Hughes and Tanner 2000) and elsewhere (Dustan and Halas 1987, Bythell et al. 1993, Edmunds 2002).

The present study addresses the population dynamics of Montastraea annularis on the shallow reefs of St. John, U.S. Virgin Islands (see Plate 1). Most of the reefs in this location have been protected within a marine protected area (MPA) since 1962 (Rogers and Teytaud 1988, Rogers and Beets 2001), but they have still changed extensively over the last 43 years (Collete and Earle 1972, Rogers and Beets 2001, Edmunds 2002). One aspect of these changes is the decline in cover of $M$. annularis at 9-m depth off Yawzi Point (Edmunds 2002), which is the subject of the present study. Using 15 years of annual surveys as a source of data on percentage cover and the fate of colonies, here we present analyses to accomplish two goals. First, we develop a demographic approach to identify the proximal causes of the changes in cover of $M$. annularis and to test whether the trend of changing cover is representative of the population dynamics. Second, we extend our demographic approach to project the population structure over 50 years and test for an effect of varying recruitment on the population structure. We selected recruitment for investigation because recruits of this species are rare throughout the Caribbean (Bak and Engel 1979, Rogers et al. 1984, Hughes and Tanner 2000), which raises the possibility that this represents an important life-history trait whereby long-lived organisms "store" the effects of infrequent successful recruitment (Warner and Chesson 1985, Edmunds 2002). Such a life-history trait is well known for many tree populations as a "masting strategy," where, over large areas and at irregular intervals, trees synchronously produce large quantities of seeds (Kelley 1994, Koenig and Knops 2005), and clearly has considerable relevance to understanding the basis of declining cover of $M$. annularis (Jackson 1992, Edmunds 2002). Unfortunately, demonstrating the occurrence of a masting effect is made difficult by the mismatch of time scales of most ecological investigations (from years to decades) vs. those relevant to long-lived organisms like $M$. annularis (from decades to centuries) (Jackson 1992). The results of the present analyses underscore the limitations of coral cover as a means to assess coral-reef condition and suggest that populations of $M$. annularis will continue to deteriorate, even within this MPA and regardless of recruitment rate, until mortality rates of established colonies decline.

\section{Methods}

Estimates of coral cover

The coral community at 9-m depth off Yawzi Point (Appendix A) was quantified using photoquadrats positioned contiguously along three permanent transects, each $10 \mathrm{~m}$ in length. The photoquadrats $(10 /$ transect) were treated as statistical replicates in a repeated measures design testing for differences among times and were recorded at least annually (twice in 1988 and 1989) from 1988 to 2003. The pictures were taken with a Nikonos V camera (Nikon, Tokyo, Japan) and 35-mm film from 1988 to 1999 and a digital camera (Nikon Coolpix 990, 3.34 megapixel resolution) from 2000 onward. In both cases, the camera was fitted with a strobe (Nikonos SB 105) and attached to a framer that held it perpendicular to the reef so that each $35-\mathrm{mm}$ frame recorded a photoquadrat $1 \times 0.75 \mathrm{~m}$ in size and each digital frame recorded a photoquadrat $1 \times 1 \mathrm{~m}$ in size. The pictures were used to determine the percentage cover of scleractinians by overlaying each image with a grid of 200 randomly placed dots and counting the dots on coral tissue. Dots on $M$. annularis were scored separately to quantify the contribution of this species to coral community structure. Because statistical indepen- 
Plate 1. View across the study reef at Yawzi Point, St. John, U.S. Virgin Islands, which has a coral fauna dominated by Montastraea annularis. The photograph shows a portion of the reef that lies along one of the transects that have been monitored since 1987 , and which provide records within photoquadrats of the fates of individual colonies (= autonomous lobes) that are the core of the present analysis. Photo credit: P. Edmunds.

dence among the photoquadrats is an important assumption of the statistical procedures applied, this assumption was examined for each transect at the start (1988) and the end (2003) of the study using von Neumann's test for serial independence (Sokal and Rohlf 1995) and the percentage cover of Montastraea annularis as a dependent variable. For all transects at both times, the quadrats were statistically independent $(0.979 \leq \eta \leq 2.468, n=10, P \geq 0.05)$ and were not significantly autocorrelated (Appendix B).

\section{Demographic analysis}

The photoquadrats were also used to quantify the density and size of individual Montastraea annularis colonies over time, and the results were used to complete a demographic analysis. Colonies were defined as autonomous areas of living coral tissue (after Connell 1973), and their fates were determined over intervals of five years (1988-1993, 1993-1998, and 1998-2003). The photographic sampling allowed colonies as small as 1$\mathrm{cm}$ diameter to be resolved, and the five-year interval provided the temporal resolution necessary to detect changes in colony sizes (i.e., growth and shrinkage).

The population structure was quantified using digital images, which, for the color slides, were obtained by scanning the originals. The digital images were used to quantify colony abundance and size-frequency distribution at the start and end of each five-year interval, as well as the fate of colonies over the same intervals.
Colony density was determined from the number of colonies in each photoquadrat, which served as a statistical replicate, and colony size was assessed as the planar area of coral tissue as measured using NIH Image 1.63 software (National Institutes of Health, Bethesda, Maryland, USA). The size-frequency distribution was prepared by measuring the size of all colonies within consecutive photoquadrats until $\sim 500$ colonies were measured. Size-frequency distributions were prepared using four size classes that were selected to span the range of colony sizes encountered and capture the dynamics of populations using size-based matrix models (Methods: Demographic models).

Population dynamics were quantified by recording whether the colonies present at the start of each interval were alive or dead at the end of the interval and, if alive, whether they had grown, shrunk, fused, or split. Colonies were tracked using the digital pictures, with those from the start and end of the intervals serving to assess changes in size and those from the intervening years being used to ensure unequivocal tracking of colonies. It was not possible to track all colonies in the photoquadrats, as some could not be relocated due to slight variations in position of the photoquadrat, impaired image quality, or uncertain colony fate (e.g., complex shapes or fusion). For colonies undergoing fusion during the study intervals, the pictures from the intervening years were used to determine which colonies were fusing, with the size of the fused colony determined 
from the picture at the end of the interval. Fission events were tracked in a similar way, with the size of the fission products determined from the picture at the end of the interval.

To gain insight into the recruitment rate of Montastraea annularis on the study reef, surveys for all juvenile corals at mostly shallower sites (five sites at $5 \mathrm{~m}$, and one at 9-m depth [described in Edmunds 2000, 2004]) between Cabritte Horn and White Point were pooled and screened for juvenile colonies (i.e., those $\leq 40-\mathrm{mm}$ diameter that were clearly not created by fission or fragmentation) of $M$. annularis complex (after Weil and Knowlton 1994). At this small size, it was not possible to distinguish among the sibling species of this taxon in situ, although the high abundance of $M$. annularis on the nearby reefs suggests that most of the recruits belonged to this species. Surveys for the abundance of juvenile corals were carried out annually between 1994 and 2004 (Edmunds 2002, 2004) and were completed using quadrats $(0.5 \times 0.5 \mathrm{~m})$ located randomly at multiple sites (mostly $>200$ quadrats per year). Juvenile coral density was recorded by genus, although several were identified to species, including $M$. annularis. Density of juvenile $M$. annularis was compared among years by pooling the data among sites.

\section{Demographic models}

Demographic models were prepared using a sizebased matrix procedure (Hughes 1984) for each of the five-year intervals. The matrices were based on four categories defined as size class I $\left(\leq 50 \mathrm{~cm}^{2}\right)$, size class II $\left(>50 \mathrm{~cm}^{2}\right.$ but $\left.\leq 150 \mathrm{~cm}^{2}\right)$, size class III $\left(>150 \mathrm{~cm}^{2}\right.$ but $\left.\leq 250 \mathrm{~cm}^{2}\right)$, and size class IV $\left(>250 \mathrm{~cm}^{2}\right)$, and the transition probabilities among size classes calculated empirically from the colony fates. Because fission was relatively common (i.e., new colonies were formed by splitting), the transition probabilities for any one size class sometimes summed to $>1$. The fate of the colonies was used to calculate the mortality rate for each size class, and the matrices were used to calculate the intrinsic rate of population growth $(\lambda)$ and the rate $(\rho)$ at which the population converged to a structure characterized by constant relative abundances of colonies in each of the four size classes (i.e., a stable size structure); $\lambda$ and $\rho$ were calculated using PopTools 2.4

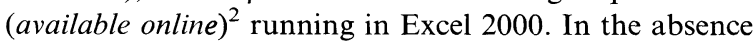
of sexual recruitment, $\lambda$ measures the rate of population decline and has a value $<1$, unless the rate of asexual proliferation exceeds mortality (Hughes 1984, Hughes and Tanner 2000); $\rho$ is inversely related to the time necessary for a population to achieve constant numbers of colonies in each size class. Elasticity matrices were also calculated using PopTools 2.4 to determine which transition probabilities had the greatest effect on population growth $(\lambda)$.

\footnotetext{
${ }^{2}\langle$ www.cse.csiro.au/cdg/poptools $\rangle$
}

The population structure of Montastraea annularis was projected by multiplying the population vector by the population matrices, starting with the population structure in the final year of this analysis (2003) and proceeding in five-year increments for 50 years. Three projections were completed. First, the population structure was projected with the assumption of no recruitment, a scenario that apparently is similar to the recent history of the study reef. Second, the population was projected with the assumption that consistent recruitment occurs. In this projection, steady recruitment, at a rate of four recruits per square meter per fiveyear period, was added to the smallest size class of the population vector. Third, the population was projected with the assumption that episodic and high recruitment occurred every 25 years at a rate of 20 recruits per square meter per 25-year period. These recruits were added to the smallest size class in the fifth iteration (i.e., the 25 th year). The rationale for the recruitment rates tested is presented in the discussion. In brief, however, the assumption of no recruitment is a conservative estimate, given that recruitment in the Yawzi Point habitat is probably too low to detect, rather than absent. In contrast, the recruitment rates applied in the second and third projection (i.e., testing the effects of consistent and episodic recruitment, respectively) were scaled to be extreme relative to the known recruitment rates of this species, simply to explore the potential for recruitment to restore the 1988 population structure of $M$. annularis. In all cases, the empirical estimates of $M$. annularis recruitment from the nearby shallow area serve to provide an ecological context within which the veracity of the recruitment scenarios tested can be evaluated.

\section{Statistical analyses}

Statistical analyses were completed using Systat version 9.2 software (SPSS, Evanston, Illinois, USA) with bootstrap estimation for the matrix parameters completed using Excel 2000. Coral cover was compared among times with a repeated-measures ANOVA using arcsine-transformed percentage-cover data. When an overall effect of time was detected, consecutive sample intervals were compared with separate repeated-measures ANOVAs. One-way ANOVA was used to compare the density of Montastraea annularis colonies among years, with post hoc multiple comparisons completed with a Bonferroni procedure. For all ANOVAs, the assumptions of normality and homoscedasticity were tested through graphical analyses of residuals; where the assumptions were not met, nonparametric procedures were used. Chi-square contingency tables were used to compare the size-frequency distributions among sampling periods, as well as the frequency of fission events among size classes.

In order to calculate variance estimates for the population parameters (mortality, $\lambda$, and $\rho$ ), a bootstrap estimation procedure was applied to the raw data describing the fate of colonies. These data were 

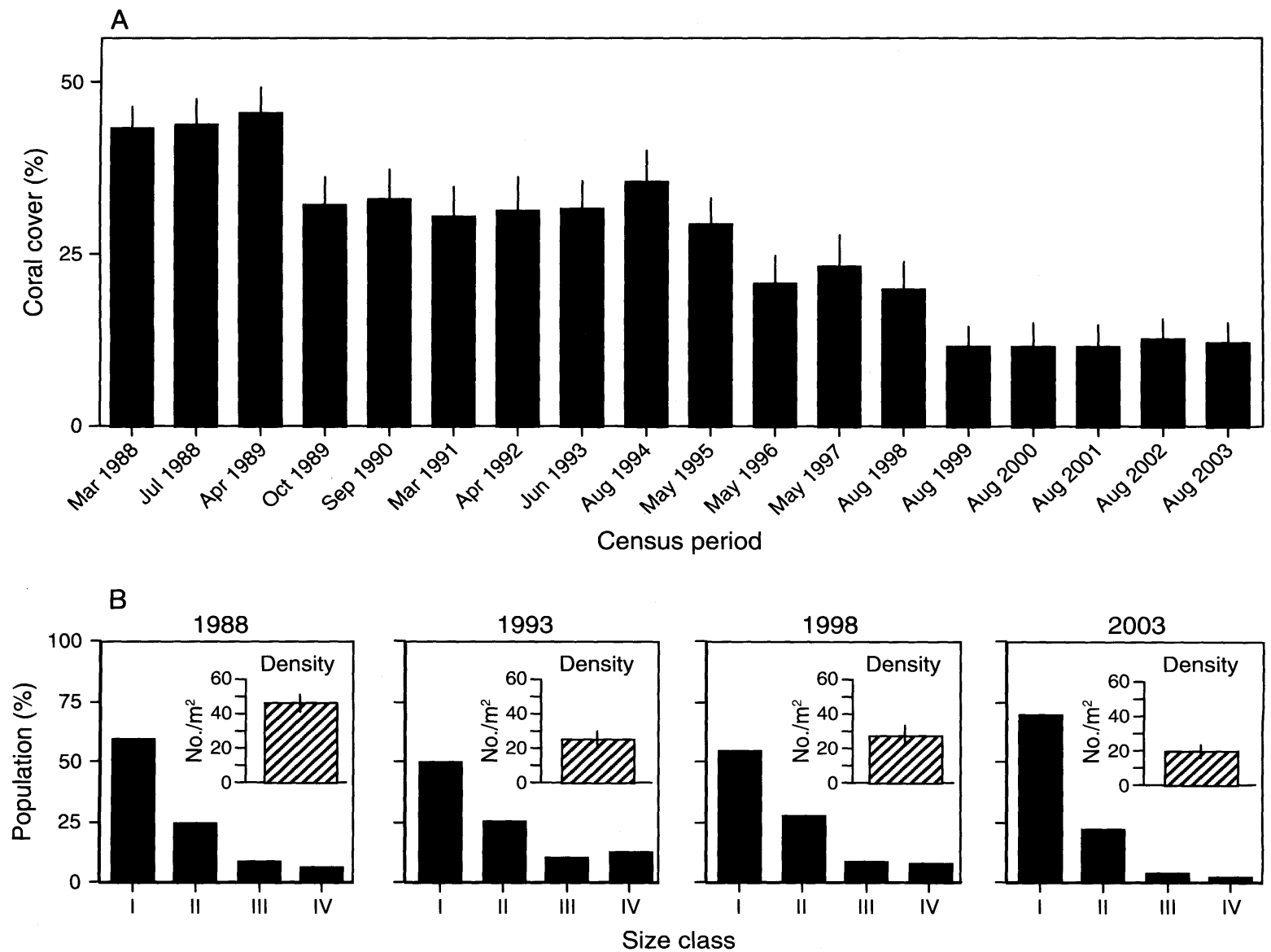

Fig. 1. Long-term trends in coral community dynamics on a reef at 9-m depth at Yawzi Point, St. John, U.S. Virgin Islands. (A) Percentage of coral cover at each survey period between March 1988 and August 2003. Note that two surveys were completed in 1988 and 1989. Means \pm SE (vertical lines above bars) are shown for sample sizes of $n=30$ quadrats/survey except October 1989 $(n=28)$, September $1990(n=29)$, and April $1992(n=20)$. Montastraea annularis accounted for $94.2 \% \pm 0.9 \%(\mathrm{mean} \pm \mathrm{SE}, n=18)$ of the coral cover in all surveys. (B) Population structure of $M$. annularis at the start and end of each five-year interval (1988-1993, 1993-1998, 1998-2003) used to construct the matrix models (Appendix C). The 1988 analysis is based on the surveys completed in March 1988. The size-frequency analyses show the percentage distribution of colonies among the size classes (I-IV, Appendix B) used to construct the matrix models ( $n=571$ colonies in 1988, 499 in 1993, 501 in 1998, and 510 in 2003). Inset graphs show the mean colony densities ( $\pm \mathrm{SE}, n=15-30$ quadrats per year).

resampled with replacement using a software routine (available online) $^{3}$ added into Excel 2000. One thousand data sets were generated with this procedure, and each was used to calculate mortality rate by size class and to create a size-based population matrix consisting of four size classes (I-IV, as previously described) that was used to calculate $\lambda$ and $\rho$ using PopTools 2.4. The resulting 1000 values for mortality, $\lambda$, and $\rho$ were used to calculate a mean and $95 \%$ confidence intervals for each metric. The confidence intervals were determined from the 2.5 th and 97.5th percentiles of the data and were used to evaluate differences between mean values for statistical significance based on nonoverlapping confidence intervals.

\footnotetext{
${ }^{3}\langle$ www.resample.com〉
}

\section{RESUlts \\ Estimates of coral cover}

Between 1988 and 2003, much of the coral cover on the study reef was lost during several periods of rapid decline beginning with the aftermath of Hurricane Hugo (September 1989) and continuing between 1994 and 1999 (Fig. 1A). Overall, coral cover differed significantly across the annual surveys $(F=50.438 ; \mathrm{df}=14,406 ; P<$ 0.001; the results from October 1989, September 1990, and April 1992 were omitted due to incomplete data sets). Separate repeated-measure ANOVAs comparing consecutive years revealed significant declines between April 1989 and October $1989(P<0.001)$, and for all pairs of years between 1994 and $1996(P \leq 0.008)$, and between 1997 and $1999(P \leq 0.013)$. Coral cover increased between 1996 and $1997(P=0.004)$, but all 


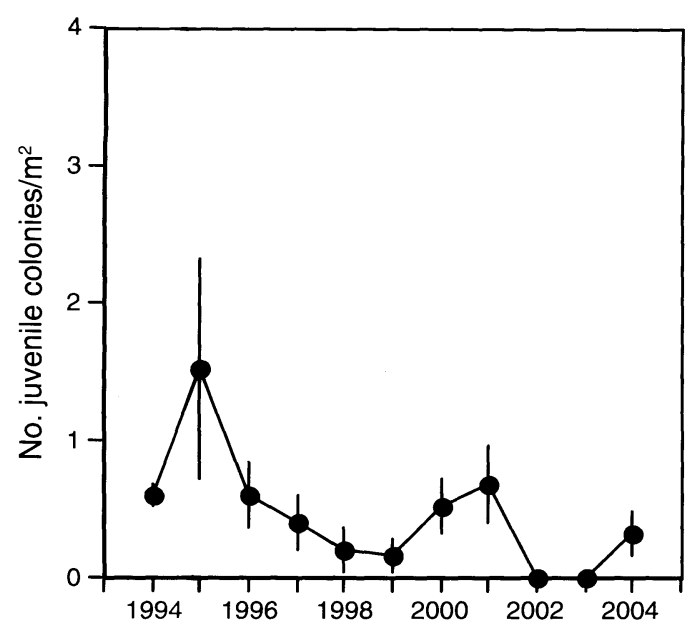

FIG. 2. Density, number of juvenile colonies $(\leq 4 \mathrm{~cm}$ diameter) per $10 \mathrm{~m}^{2}$ of Montastraea annularis complex in St. John between 1994 and 2004. Values were obtained from quadrats $\left(0-25 \mathrm{~m}^{2}\right)$ censused at two sites in $1995(n=80)$, five sites in 1994 and 1996-1998 $(n=200)$, and six sites in 1999-2004 $(n=240)$. Five of the sites were at 5-m depth, with the sixth (included in the surveys from 1994) at 9-m depth; means \pm SE are shown.

other consecutive sampling intervals, statistically, were indistinguishable, including those from 1999 to 2003. Between 1988 and 2003, coral cover declined by $72 \%$ (from $43.4 \%$ to $12.3 \%$ ), but remained unchanged among the five most recent sampling years. Montastraea annularis remained the dominant scleractinian throughout the study, accounting for a mean of $94.2 \% \pm 0.9 \%$ of the coral cover in the 18 sampling years $( \pm \mathrm{SE}, n=18)$. The majority $(94.7 \%)$ of the coral cover was composed of M. annularis in March 1988, and by 2003, this had declined slightly to $90.3 \%$.

\section{Demographic analysis}

In concert with the decline in cover of Montastraea annularis, both the size-frequency distribution and density of colonies changed. The four size-frequency estimates at five-year intervals $(1988,1993,1998,2003)$ varied over time $\left(\chi^{2}=67.837, \mathrm{df}=9, P<0.001\right)$, largely due to a reduced number of larger colonies and an increased number of smaller colonies in the more recent intervals (Fig. 1B). However, both small $\left(1-2 \mathrm{~cm}^{2}\right)$ and large colonies $\left(>700 \mathrm{~cm}^{2}\right)$ were found in all intervals, and in 1993, three of the 499 colonies tracked were $\geq 1215 \mathrm{~cm}^{2}$ in area. Additionally, the density of colonies varied among the four years that are representative of trends in coral cover across the three intervals $(F=$ 5.632, $\mathrm{df}=3,100, P=0.001$ ). Overall, the population density of $M$. annularis declined from a mean of 47 colonies $/ \mathrm{m}^{2}$ in 1988 to 20 colonies $/ \mathrm{m}^{2}$ in 2003 (a $57 \%$ reduction), with the densities of colonies in 1998 and 2003 differing from the density in $1988(P \leq 0.040)$. No other pairwise comparisons were significant $(P \geq 0.069)$.
The best estimate of the recruitment of Montastraea annularis to the study reef comes from surveys for juvenile corals (i.e., $\leq 40-\mathrm{mm}$ diameter) in mostly shallower areas of the same bay. In comparison to the deeper reef areas, the shallow reefs facilitated the unambiguous detection of coral recruits and juveniles because they consist of large areas of relatively smooth rock upon which small corals are easily detected (Edmunds 2000). In these surveys, large areas of reef were sampled (up to $60 \mathrm{~m}^{2}$ ) annually between 1994 and 2004, and juvenile colonies of the M. annularis complex were found at densities ranging from 0 colonies $/ 10 \mathrm{~m}^{2}$ to 1.5 colonies $/ 10 \mathrm{~m}^{2}$ (Fig. 2). These densities did not vary significantly among the 11 years surveyed (KruskalWallis test, $H=10.365, n \geq 80$ quadrats/yr, $P=0.409$ ). On the actual study reef, the high topographic complexity of the substratum, the high abundance of small colonies of $M$. annularis produced by fission (Fig. 3), made it problematic to unequivocally identify sexual recruits. However, attempts to survey small areas on this reef (30 quadrats each of $0.25-\mathrm{m}^{2}$ area) for juvenile colonies of $M$. annularis between 1996 and 2004 suggest that small colonies of this species (i.e., colonies $\leq 40-\mathrm{mm}$ diameter that are a combination of juveniles plus small fission products) occur at densities of $\sim 1.8$ colonies $/ 10$ $\mathrm{m}^{2}$, which is similar to the highest density recorded in shallower water (Fig. 2). Overall, the 11 years of surveys in shallow water provide a mean population density of juvenile $M$. annularis of $0.36 \pm 0.08$ colonies. $(10$ $\left.\mathrm{m}^{2}\right)^{-1} \cdot \mathrm{yr}^{-1}$ (mean $\pm \mathrm{SE}, n=2316$ quadrats [pooled among times]), and therefore we conservatively estimate

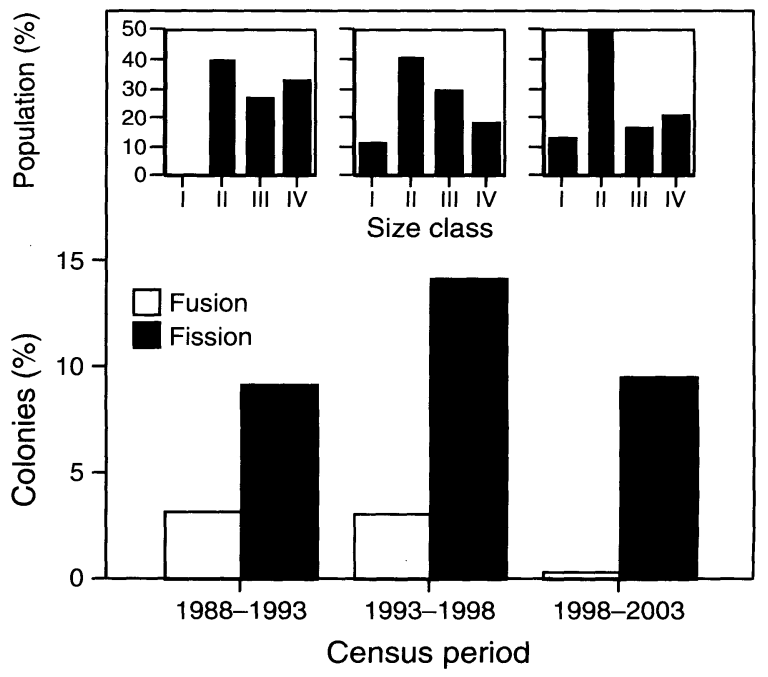

FIG. 3. Percentage of Montastraea annularis colonies undergoing fusion or fission over three survey intervals between 1988 and 2003. Sample sizes are 326 colonies between 1988 and 1993, 309 between 1993 and 1998, and 250 between 1998 and 2003. Inset graphs show the percentage allocation of colonies undergoing fission among four size classes (I-IV; Appendix C). Sample sizes are 30 colonies between 1988 and 1993, 44 between 1993 and 1998, and 24 between 1998 and 2003. 
that the recruitment rate of this species to the study reef did not exceed this value.

\section{Demographic models}

Analyses of the photoquadrats identified 326 colonies that could be tracked between 1988 and 1993, 309 colonies between 1993 and 1998, and 250 colonies between 1998 and 2003. Most colonies ( $\geq 75 \%$ ) were in size classes I and II for all time intervals; fewer were found in the larger size classes (III and IV), especially in the final time interval (Appendix $\mathrm{C}$ ). The reduction across the three time intervals in number of colonies that could be tracked reflects the difficulty of locating colonies as the population density declined by $57 \%$ (Fig. 1). For the colonies that could be tracked, their fates varied but were strongly biased towards death, stasis, or shrinkage (Appendix C). Between $4.7 \%$ and $13.5 \%$ of the colonies in the smaller size classes (i.e., I, II, and III) grew into larger size classes between 1988 and 1993 , but $\leq 5.3 \%$ of the colonies in the smaller size classes grew into larger size classes in the two subsequent intervals (Appendix C). However, relatively large numbers of colonies were affected by fission and fusion, and in some cases, fission resulted in a net increase in colony numbers so that the transition probabilities for each size class summed to $>1$ (Appendix C).

When colony abundances were highest (1988-1993), $3.3 \%$ ( 11 colonies) of the colonies fused, and this rate remained largely unchanged (3.2\% [10 colonies]) over the next interval (1993-1998), finally declining to $0.4 \%$ (one colony) between 1998 and 2003 (Fig. 3). The proportion of colonies undergoing fusion among the three study intervals changed significantly $\left(\chi^{2}=6.266, \mathrm{df}\right.$ $=2, P=0.043)$, largely because of the small numbers fusing between 1998 and 2003. The relative number of colonies undergoing fission was indistinguishable among the three intervals $\left(\chi^{2}=4.856, \mathrm{df}=2, P=0.088\right)$, and the number of colonies undergoing fission was independent of the size class and study intervals (Fig. $3 ; \chi^{2}=6.807$, df $=6, P=0.339$ ).

Mortality rates (per five-year period) were highest $(\geq 36 \%)$ for size classes I and II for each of the three intervals but still were $\geq 11 \%$ in size classes III and IV. The highest mortality rate (56\%) was recorded for corals in size class I over the final interval (1998-2003; Appendix C). Based on the $95 \%$ confidence intervals for mortality rates obtained by bootstrap resampling, mortality rates displayed differences among size classes that differed between sampling intervals (i.e., there was a sampling interval $\times$ size class interaction). This effect appears to be caused largely by the mortality rates for size classes III and IV in the 1993-1998 interval, both of which have confidence intervals that are non-overlapping with those for size class $I$ in all sampling intervals (Fig. 4).

The transition matrices were dominated by high rates of mortality and shrinkage, and therefore the intrinsic rates of population change $(\lambda)$ all are $<1$ (i.e., the
FIG. 4. Percentage mortality of Montastraea annularis colonies in four size classes (I-IV; Appendix C) over three five-year intervals between 1988 and 2003. Values shown are means $\pm 95 \%$ CI that were obtained by a bootstrap sampling procedure (1000 iterations) of the original data.

population was declining over each interval [Appendix C]). These values show that the population decline slowed by $2 \%$ over the second interval $(\lambda=0.673)$ compared to the first interval $(\lambda=0.661)$, but the decline accelerated by $14 \%$ in the final interval $(\lambda=0.581)$ compared to the second interval; this trend was not significant as assessed from the overlapping 95\% confidence intervals for $\lambda$, obtained by bootstrap resampling (Appendix $D$ ). The damping ratio ( $\rho$ ) provides a relative measure of the rate at which a cohort converges to a stable size structure, and in the present analysis reveals a slight increase in tempo (i.e., $\rho$ increases) of population dynamics over the 15-year period. Based on the replicate values of $\rho$ obtained by bootstrap resampling, the mean values for $\rho$ were similar in the first two sampling intervals, 'but a 7\% increase occurred between the second and the third interval; this trend was not significant as assessed from the overlapping 95\% confidence intervals (Appendix D).

The elasticity matrices (Appendix $C$ ) reveal the proportional sensitivities of $\lambda$ to changes in each of the transition probabilities, with the largest elasticity indicating the transition probability with the greatest effect on $\lambda$. The relative values of the elasticities vary among the three intervals; with the stasis of size class II colonies (i.e., the II-II transition probability) having the greatest effect on $\lambda$ for the first (elasticity $=0.224$ ) and third intervals (elasticity $=0.326$ ), and the stasis of size class IV colonies having the greatest effect on $\lambda$ for the second interval (elasticity $=0.215$ ). In the first and third intervals, a $10 \%$ change in the II-II transition probability would alter $\lambda$ by $2 \%$ in the firśt interval, and $3 \%$ in 

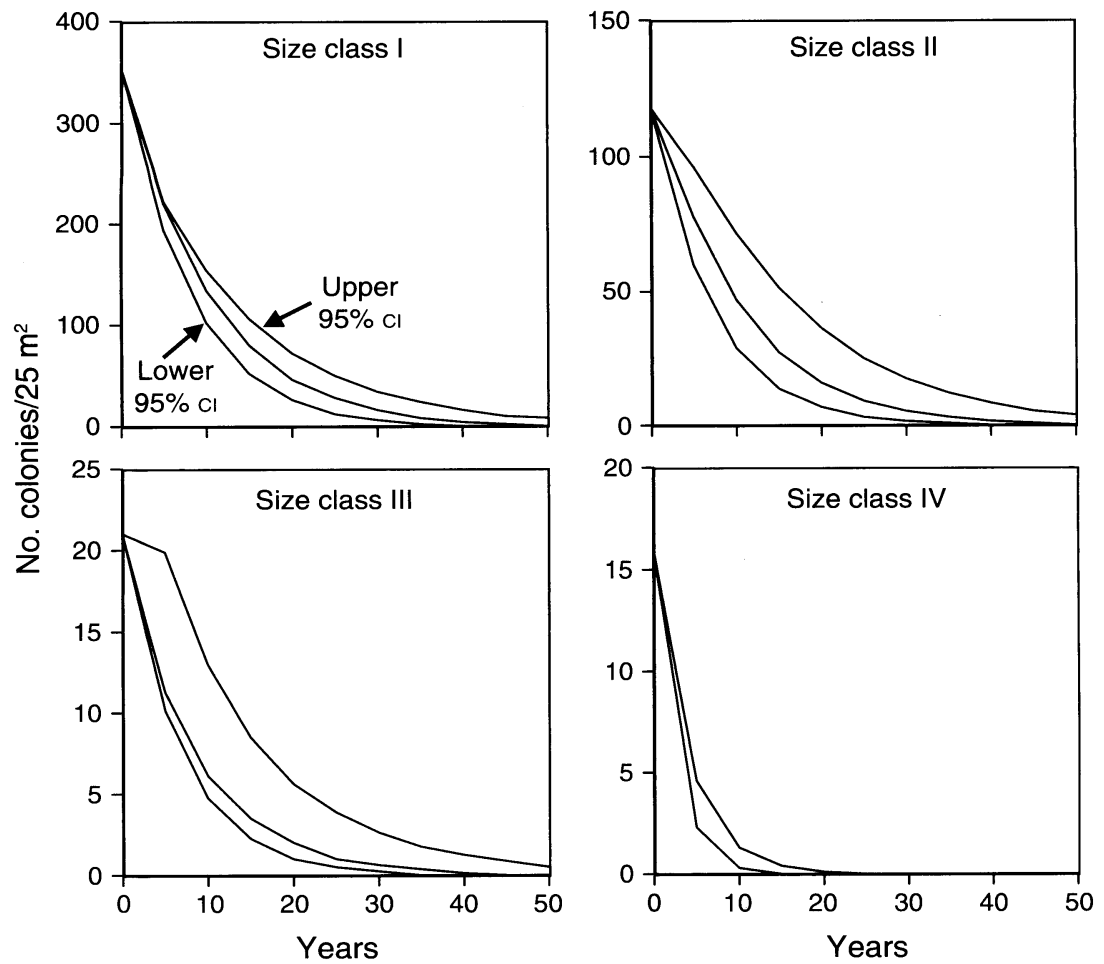

FIG. 5. Fifty-year population projection by size class (I- IV; Appendix C) for Montastraea annularis, assuming that recruitment does not occur. Projections are based on an initial population vector determined from the population structure in $25 \mathrm{~m}^{2}$ of the study reef in 2003 (Fig. 1B; 355, 118, 21, and 16 colonies in each of size classes I, II, III, and IV, respectively), and trajectories were calculated in five-year increments using the transition matrix from 1998-2003 (for which $\lambda=0.581$; Appendix C), as well as the bootstrapped matrices corresponding to the $95 \%$ confidence intervals (CI) for $\lambda$ (Appendix D). For size classes I-III, the projections based on the $95 \%$ CI for $\lambda$ flank the projections based on the actual matrix. For size class IV, the projection for the upper $95 \%$ CI were lower than the projection for the actual matrix and therefore are not shown.

the third interval; in the second interval, a $10 \%$ change in the IV-IV transition probability would alter $\lambda$ by $2 \%$.

To better understand how the study reef might change in the future, the population was projected over 50 years. The first projection assumed that the 2003 conditions continued without recruitment of Montastraea annularis and started with the population vector defined by the number of colonies in $25 \mathrm{~m}^{2}$ of reef in 2003: $355,118,21$, and 16 colonies in each of size classes I, II, III, and IV, respectively. We set recruitment to 0 instead of using the recruitment rate estimated from nearby shallower areas (Fig. 2) because of uncertainty regarding the reliability of extrapolating these data to a deeper site with different substratum characteristics; a projection completed with the recruitment set to $0.04 / \mathrm{m}^{2}$ (the mean density of juvenile $M$. annularis recorded in the shallower areas [Fig. 2]) revealed an outcome very similar to that obtained with 0 recruitment (P. J. Edmunds, unpublished data). The projection was completed using the matrix from 1998-2003 (Appendix C) and two additional matrices corresponding to the $\lambda$ values marking the upper and lower 95\% confidence intervals for this metric. Even though the percentage of coral cover appeared to have stabilized at $\sim 12 \%$ between 1999 and 2003 and did not change significantly over this period (Fig. 1), the projection reveals an imminent population collapse. Within 25 years, the largest colonies of $M$. annularis $\left(>250 \mathrm{~cm}^{2}\right)$ will be dead, and within 50 years, the population density of colonies in the other three size classes will be 0 , or near-zero, regardless of the intrinsic rate of population growth $(\lambda)$ within the 95\% confidence intervals (Figs. 5 and 6).

The second and third projections were selected to incorporate two scenarios of recruitment of Montastraea annularis and, again, were calculated using the matrix from 1998 to 2003 (Appendix C). The goal of these projections was to gain insight into the potential for recruitment to ameliorate the population decline that has taken place between 1988 and 2003. The second projection was identical to the first, but with the addition of recruitment to size class $I$ at a rate of 4 corals $\cdot \mathrm{m}^{-2} \cdot(5 \mathrm{yr})^{-1}$. This rate of recruitment is $\sim 20$-fold higher than the best estimate of the mean recruitment rate for this species to the study reef, as determined from the surveys for juvenile corals to nearby areas. Recruitment augmented the number of corals in size class I, with the formation of a near-stable size class I density at $\sim 52 \%$ of the initial value after $\sim 30$ years. Size 
A) No recruitment

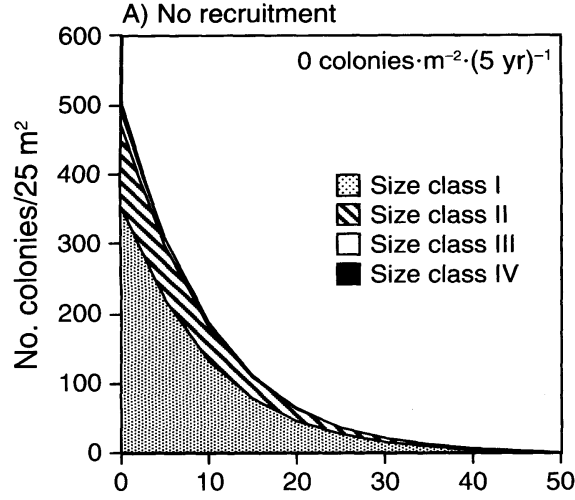

B) Steady recruitment

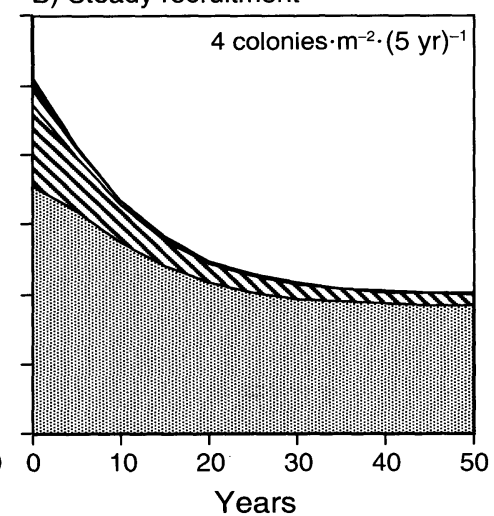

C) Episodic recruitment

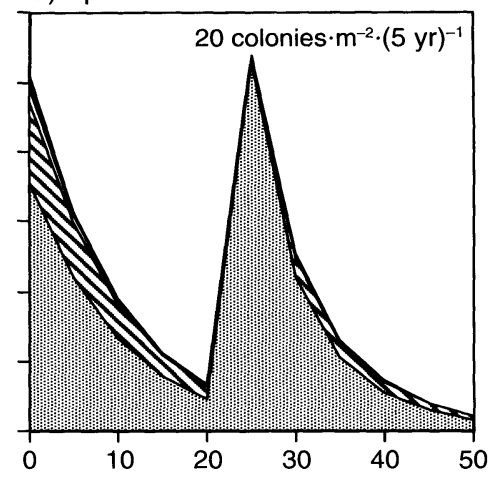

FIG. 6. Fifty-year population projections by size class (I-IV; Appendix C) for Montastraea annularis, under three scenarios of recruitment: (A) no recruitment (the same projection shown in Fig. 5), (B) steady recruitment at 4 colonies $\mathrm{m}^{-2} \cdot(5 \mathrm{yr})^{-1}$, and (C) episodic recruitment at 20 colonies $\cdot \mathrm{m}^{-2} \cdot(25 \mathrm{yr})^{-1}$. Projections are based on an initial population vector determined from the population structure in $25 \mathrm{~m}^{2}$ of the study reef in 2003 (described in Fig. 5), and trajectories were calculated in five-year increments using the transition matrix for 1998-2003 with recruitment (where appropriate) added to size class I at each iteration.

class II reached a near-stable density at $\sim 13 \%$ of the initial density. Steady recruitment at a high rate, however, failed to return the population density of the largest colonies (size class III and IV) to the levels marking the start of the third interval or the start of the study (1988). The third projection was identical to the first, except that episodic recruitment added a large number of recruits $\left(20\right.$ corals $\left.\cdot \mathrm{m}^{-2} \cdot(25 \mathrm{yr})^{-1}\right)$ to size class I after 25 years. This level of recruitment was selected to mimic putative masting of this species (Edmunds 2002) on a time scale compatible with the length of the working career of marine ecologists. This time scale is important as it allows a test of the possibility that researchers have not recorded high recruitment of this species because it occurs infrequently. Episodic recruitment in the 25th year added transiently large numbers of corals to size class I, but had a negligible effect on the number of colonies in size classes II, III, and IV. Following episodic high recruitment, the population density declined rapidly to $<3 \%$ of the starting population size (510 colonies) at the end of the 50-year projection (Fig. 6). The notable outcomes of these three projections are that (a) the present-day population (i.e., in 2003) of M. annularis in Great Lameshur Bay is facing imminent collapse and (b) recruitment alone cannot prevent the collapse or replace the size class III and IV colonies that were important components of the 1988 population structure. This will require changes in the transition probabilities describing the fate of established colonies.

\section{DISCUSSION}

Globally declining coral abundances (Gardner et al. 2003, Bellwood et al. 2004) and a diversity of anthropogenic disturbances that continue to kill scleractinian corals (Brown 1997, Knowlton 2001, Buddemeier et al. 2004) have occurred against a backdrop of century-scale human exploitation that, arguably, has left no coral reef in a pristine state (Jackson et al. 2001). Not surprisingly then, the prognosis for coral reefs is so poor (Knowlton 2001, Gardner et al. 2003, Bellwood et al. 2004) that scientists are beginning to ask which corals will survive this onslaught and how their populations will change (McClanahan 2002, Hughes et al. 2003, Buddemeier et al. 2004). In the present study, a 15-year record of coral cover on one reef in St. John provided the context for a demographic analysis of Montastraea annularis that was designed to determine how the population structure of this species has changed and how it might continue to change in the near future. The analysis revealed that the decline in coral cover was largely a result of high mortality rather than low recruitment and was accompanied by a disproportionately large reduction in the abundance of big colonies $\left(>250 \mathrm{~cm}^{2}\right)$ that was accentuated by fission (affecting $>9 \%$ of the colonies), even while the population density declined 52\%. By the end of the study, coral cover had stabilized at a reduced level, but the demographic analysis revealed that the rate of population decline $(\lambda)$ and the overall tempo of change $(\rho)$ continued at the same pace (i.e., $\lambda$ and $\rho$ did not vary statistically over 15 years), and perhaps even accelerated (i.e., there was a trend for $\lambda$ and $\rho$ to increase).

Between 1988 and 2003, the study reef lost $72 \%$ of its coral cover, with rapid declines occurring in 1989 due to Hurricane Hugo (Edmunds and Witman 1991, Rogers et al. 1991) and between 1994 and 1999, a period marked by two serious hurricanes in 1995 (Smith et al. 1997) and a year (1998) of unusually warm seawater temperatures (Edmunds 2004). The trend of declining coral cover is representative of other sites around St. John (Rogers et al. 1991, Rogers and Miller 2006; P. J. Edmunds, unpublished data), although a slight increase in coral cover has occurred over a similar period on at least one 
reef $<1 \mathrm{~km}$ from Yawzi Point (Edmunds 2002). In part, such discrepancies may reflect the biases that can develop when study sites are not chosen randomly (Hughes 1992, Lewis 2004), but in the case of our work in St. John, it is important that the dissimilar trends of changing coral cover occurred at two sites that were both chosen in 1987 based on high coral cover $(\geq 32 \%)$ (Edmunds 2002). The contrasting trajectories illustrate that the community dynamics were not constrained entirely by their initial condition (sensu Hughes 1992). This also was true within a site, for at Yawzi Point, the 15-year decline in coral cover was more rapid along two of the three transects, where coral cover declined from $35-45 \%$ in 1988 to $3-6 \%$ in 2003, compared to the third, where coral cover declined from $50 \%$ in 1988 to $27 \%$ in 2003 (P. J. Edmunds, unpublished data). It is unknown whether these small-scale patterns are biologically significant when interpreted within the framework of region-wide reef decline (Gardner et al. 2003), but signs that some areas of reef are doing better than the majority of reefs is cause enough to study such patterns further.

When placed in a global context, the loss of coral at Yawzi Point is equivalent to the losses that have been reported from Jamaica (Hughes 1994) and throughout the Caribbean (Gardner et al. 2003); it is $\sim 1.4$-fold higher than the $\sim 50 \%$ loss that has occurred on parts of the Great Barrier Reef (Bellwood et al. 2004). While large amounts of coral died between 1988 and 1999 at this site in St. John, coral cover apparently stabilized at $\sim 12 \%$ during the most recent five-year interval. This interval included three years (1998-2000) that were incorporated into the meta-analysis of Gardner et al. (2003) and contributed, in part, to their conclusion that the rate of loss of coral cover has recently slowed throughout the region. In St. John, the death of $M$. annularis colonies was important because it reduced coral cover, but significantly, it also created vacant space that was preempted by macroalgae (Rogers et al. 1997, Edmunds 2002) and probably depressed the frequency of fusion (from 3.3\% over 1988-1993 to $0.4 \%$ over 1998 2003) by preventing conspecific contacts (i.e., colonies were too far apart to touch). After 11 years of declining coral cover, linear extrapolation from the most recent five years could be construed as support for "guarded optimism" concerning the likelihood of further coral losses (Gardner et al. 2003). However, optimism may be premature for this reef. Population projections based on the dynamics of colonies and the conditions prevailing between 1998 and 2003 demonstrate the high likelihood that the local population of $M$. annularis will be extirpated within 50 years.

There are strong parallels between the changes in coral community structure in St. John and those reported previously for Jamaica (Hughes and Tanner 2000). Notably, the reefs in both locations started their study periods dominated by Montastraea annularis, they suffered large losses of coral on a decadal scale, in part as a result of hurricane damage, and both displayed disconnects between coral community trajectories determined by coral cover vs. demographic analyses. Moreover, just as is reported here for St. John, in Jamaica, the population decline was most sensitive to the mortality of the largest colonies of $M$. annularis, and over time, the population size structure became positively skewed (Hughes and Tanner 2000). However, there also are important differences between these studies, namely that the St. John reef is in shallower water (9-m depth) than the Jamaican reef (35-m depth), and the St. John study was initiated a decade after the Jamaican study began and when it was already recording $\sim 50 \%$ reductions in coral cover (Hughes and Tanner 2000). Additionally, the St. John reef is set in a local-scale context (sensu Mittelbach et al. 2001) that is protected within an internationally-recognized MPA and is substantially less degraded than many reefs in Jamaica (Hughes 1994, Aronson and Precht 2001a). Against this backdrop, a comparison of the community dynamics in both locations provides a poor prognosis for other Caribbean reefs where large populations of $M$. annularis are found. Most important in this context is the observation that a "Jamaican-like" collapse (Hughes 1994) of the St. John reef did not occur contemporaneously with that occurring in Jamaica, at least based on anecdotal underwater pictures from St. John that were taken during the early 1970s (generously loaned by C. Birkeland; see also Figs. 45-48 in Lee et al. 1975), but instead it began nearly a decade later with Hurricane Hugo (Fig. 1).

Although the causal processes of reef decline were not identical in Jamaica and St. John (Hughes 1994, Edmunds 2002), the outcome with regard to overall coral cover appears, broadly, to have been similar. For most of the 1980s, the study reef in St. John represented a "patch" of reef that apparently differed in condition compared to the larger patch of reef along the north coast of Jamaica. While patches of apparently healthy coral reef still occur at various spatial scales throughout the Caribbean, for example at the Dairy Bull site in Jamaica (Edmunds and Bruno 1996, Idjadi et al. 2006) and at the Tektite reef in St. John (Edmunds 2002), the present study suggests that such patches may be located at different points on the same downward trajectory of reef condition and may differ from one another in their disturbance histories that propel them along this trajectory. Demographic analyses of the coral populations on such "healthy patches" provide one potential method to test this hypothesis explicitly (i.e., that the patches are following the same trajectories at different rates), although it is likely that the demographic patterns will, to some extent, be unique to each reef (Done 1988).

In St. John, the mortality rates of Montastraea annularis differed among size classes in a pattern that varied among sample intervals, largely because the mortality of the larger colonies (11-39\% per five years for size classes III and IV) was reduced between 1993 
and 1998, at least compared to the other sample intervals. Smaller colonies $\left(\leq 150 \mathrm{~cm}^{2}\right)$ had high mortality rates $(35-56 \%$ per year) in all three intervals. The mortality rates of massive corals in other studies vary greatly depending on species, location, disturbance regime, and size class (Done 1988, Babcock 1991, Bythell et al. 2000, Hughes and Tanner 2000). Mortality rates as low as $<1 \%$ per year have been reported for $M$. annularis (Bythell et al. 2000) and as high as $90 \%$ for small colonies $(<30 \mathrm{~cm}$ diameter) of massive Porites exposed to Acanthaster planci predation (based on censuses completed 6-7 years after the outbreak; Done 1988). Typically, mortality declines with size; for instance, Babcock (1991) found that small colonies $\left(<40 \mathrm{~cm}^{2}\right)$ of Goniastrea aspera on the Great Barrier Reef died at a rate of $32 \%$ per year, while larger colonies $\left(>120 \mathrm{~cm}^{2}\right)$ died at a rate of $5 \%$ per year. In the Jamaican study of $M$. annularis by Hughes and Tanner (2000), mortality rates (per five years) between 1977 and 1982 ranged from $43 \%$ to $3 \%$ for the smallest $\left(\leq 50 \mathrm{~cm}^{2}\right)$ to largest $\left(>200 \mathrm{~cm}^{2}\right.$ ) colonies, respectively, but between 1987 and 1993, these rates had accelerated dramatically to $86 \%$ and $38 \%$, respectively.

However, the biological significance of high mortality rates depends on the demographic process acting to replace the colonies. The effects of coral mortality can be offset by rapid growth and recruitment, thereby conferring resilience (the rate of regrowth) to the effects of disturbance (Andres and Rodenhouse 1993). In the present study, the mortality rates of the larger colonies were high relative to the slow rate at which smaller colonies transitioned (i.e., grew) into these larger size classes $(<11 \%$ per five years), thereby creating a demographic inequality. The significance of this inequality is accentuated by the $\geq 100$ years required for a recruit of $M$. annularis to grow at a typical rate of 1-1.5 $\mathrm{cm} / \mathrm{yr}$ (Hudson 1981, Hughes and Jackson 1985) into a colony in the largest size class (with an area $>250 \mathrm{~cm}^{2}$ and a height of $\sim 1 \mathrm{~m}$ [P. J. Edmunds, unpublished data]), and the high chance $(>17 \%$ per five years) that it will die in this size class. A similar demographic inequality affects massive Porites on the Great Barrier Reef (Done 1987, 1988). Given the plethora of events that are currently killing corals, there is clearly an important need to evaluate the ecological significance of coral death within a demographic context.

The projected collapse of the study population of Montastraea annularis assumes that recruitment is effectively 0 . The rationale for this assumption lies in the paucity of recruits of this species throughout the Caribbean (Bak and Engel 1979, Rogers et al. 1984) including, for instance, at 35-m depth in Jamaica where Hughes and Tanner (2000) found only one recruit of $M$. annularis during 16 years of annual surveys of $12 \mathrm{~m}^{2}$ of reef. In the present study, we estimated recruitment of $M$. annularis from adjacent fringing reefs, yet even in these areas where it is relatively easy to detect small corals (Edmunds 2000), we have rarely encountered juveniles of $M$. annularis, with those that we have found amounting to only $0.04 / \mathrm{m}^{2}$. Without recruitment, the projection revealed that the 2003 population of $M$. annularis will disappear within 50 years, with this outcome being unaffected (although altered slightly in rate) by the use of different matrices corresponding to the $95 \%$ confidence intervals for $\lambda$.

As a means to further explore the factors contributing to the projected population collapse, we tested two recruitment scenarios using a projection approach. Recruitment was selected for manipulation in order to test the hypothesis that coral populations are controlled to some extent by recruitment (Done 1987, 1988, Caley et al. 1996, Hughes et al. 2000, Raimondi and Morse 2000), which, if elevated, would increase population size as a function of a stock-recruitment relationship. Given the open nature of populations of most marine organisms with dispersive pelagic larvae (Caley et al. 1996), like the broadcasting spawning members of the Montastraea annularis species complex (Levitan et al. 2004), it is likely that any stock-recruitment relationship for this species would only be loosely defined (Caley et al. 1996). Nevertheless, recruitment has an inevitable demographic link with population size (Hughes 1984, Caswell 2001); therefore, on a time scale commensurate with the lifespan of coral colonies, varying recruitment rates should have a trickle-down effect on population structure (Done 1987, 1988). For at least one weedy coral, the brooding Caribbean coral Porites astreoides, the stock-recruitment relationship appears to be well developed, with population growth being sensitive to changes in rates of recruitment (Lirman and Miller 2003).

For long-lived corals, like massive Porites on the Great Barrier Reef and Montastraea annularis in the Caribbean, recruitment is intriguing because, theoretically, a colony living for centuries need produce only one recruit during its lifespan to sustain the population size. This assertion appears to be consistent with the low rates of recruitment of both $M$. annularis previously discussed and massive Porites (Dunstan and Johnson 1998, Hughes et al. 1999); although in contrast to $M$. annularis, juvenile colonies of massive Porites are common on Pacific reefs (Done 1987). A life-history strategy with a large adult population but rare recruitment has been described in a general form as the storage effect, whereby a population of old individuals (e.g., many corals and certain trees) "stores" a historic recruitment signal until another episodic recruitment event occurs (Warner and Chesson 1985). In what may be an extreme example of this phenomenon, sexual recruitment of the common native tree Populus tremuloides (quaking aspen) in the Rocky Mountains of North America is thought to occur on a time scale of hundreds to thousands of years during rare "windows of opportunity" (Romme et al. 2005). Unfortunately, it is difficult to demonstrate the existence of a storage effect because the passage of years or 
decades without significant sexual recruitment can lead to the incorrect conclusion that biologically meaningful recruitment does not occur. Interestingly, for $M$. annularis, the available data indicate that populations rarely contain recruits, yet this species allocates substantial resources to reproduction (Szmant 1991) that are released in an annual mass-spawning event in the late summer to early fall (Knowlton et al. 1997, Szmant et al. 1997, Levitan et al. 2004), which results in relatively high fertilization rates (Levitan et al. 2004).

Successful reproduction, yet poor recruitment, by Montastraea annularis could reflect the consequence of multiple processes influencing pre-settlement (Gaines and Roughgarden 1985) and post-settlement events (Gosselin and Qian 1997), but distinguishing among these possibilities is currently beyond the scope of the available data. However, regardless of the mechanism(s) mediating the recruitment success of $\boldsymbol{M}$. annularis, the likelihood that the end result is ecologically significant recruitment on a time scale of decades to centuries (or longer) warrants further attention. Empirical support for this possibility comes from cores taken offshore through the reef rock of Barbados (Fairbanks 1989, Jackson 1992), the stratigraphy of which reveals the disappearance and reestablishment of populations of $M$. annularis within several centuries (Fairbanks 1989). Moreover, at least three of the cores contain evidence of multiple, temporally independent populations of $M$. annularis that are separated on a time scale as long as $\sim 10000$ years (Fairbanks 1989). Because the asexual products (i.e., colony fragments or small lobes) of $M$. annularis are generally too heavy to disperse large distances (but see Edmunds and Witman 1991), the periodic reestablishment of $M$. annularis populations that is suggested by the Barbados cores (Fairbanks 1989) probably occurred through sexual recruitment. If this assertion is correct, then the large recruitment events of $M$. annularis in Barbados did indeed occur at such infrequent intervals (i.e., with events separated by at least centuries) that, had they occurred in the 20th century, would have easily avoided detection by ecologists. From our work in St. John, it is clear that recruits of $M$. annularis are available at very low numbers, and we have used DNA fingerprinting techniques to demonstrate that at least 10 nearby colonies of $M$. annularis on the study reef are genetically distinct (P. J. Edmunds, unpublished data) and therefore are the products of sexual recruitment. Thus, sexual recruitment of unknown magnitude occurs in the study populations of $M$. annularis at some temporal scale. It was our intention to explore this possibility further using additional population projections employing differing recruitment scenarios.

The first projection tested the effect of yearly recruitment elevated 27 -fold above the density we recorded on the shallow reefs, and the second tested one aspect of the storage effect hypothesis (episodic high recruitment [Warner and Chesson 1985]) by elevating recruitment $>100$-fold above that recorded in shallow water and applying it once after 25 years. However, over the 50-year projections, neither of these scenarios restored the population structure characteristic of either 2003 (the start of the projection) or 1988 (the start of this study). Stable recruitment prevented population collapse but created a population dominated by small colonies $\left(<50 \mathrm{~cm}^{2}\right)$, and episodic, high recruitment created a transient pulse of small colonies but did not prevent subsequent population collapse. Both outcomes illustrate the strong influence of the transition matrix that was used in the projections (Appendix C), or in other words, the projected population structure was relatively insensitive to recruitment, yet strongly affected by the fate of existing colonies. This conclusion was supported by the elasticity analyses, which demonstrated that $\lambda$ was sensitive to the proportion of colonies remaining in specific size classes for the duration of each interval. For the 1988-1993 and 1998-2003 intervals, the colonies remaining in size class II had the greatest effect on $\lambda$, but between 1993 and 1998, the colonies remaining in size class IV had the greatest influence on $\lambda$. Because $\lambda$ is an indirect measure of fitness (McPeek and Peckarsky 1998, Ebert 1999), high elasticities can be used to indicate portions of the life cycle that are under the strongest selective pressure, and which might be best targeted by resource managers for the purpose of population conservation (Ebert 1999, Caswell 2001). For $M$. annularis, these portions are the Class II and Class IV colonies $\left(51-150 \mathrm{~cm}^{2}\right.$ and $\left.>250 \mathrm{~cm}^{2}\right)$ in both St. John and Jamaica (Hughes and Tanner 2000).

The dominance of coral population by small colonies (i.e., positive skewing) is a common response of coral populations to environmental assaults (Fong and Glynn 1998, Done 1999, Hughes and Tanner 2000), which has been interpreted as a skewing to an earlier successional stage (Done 1999). For massive species like Montastraea annularis, a trend with time for decreasing colony size can also reflect the demographic advantages of asexual proliferation within the constraints of a habitat crowded with conspecific colonies (Lasker and Sanchez 2002). In contrast, some coral populations respond to environmental assaults in the opposite direction, that is with their population structure becoming negatively skewed (i.e., dominated by big colonies) in disturbed habitats (Bak and Meesters 1999, Meesters et al. 2001) or when growth is accelerated (Andres and Rodenhouse 1993), such as by exposure to rising seawater temperature (Fong and Glynn 2000, Edmunds 2005). The reasons for these opposing trends are unclear, but it is likely that the disturbance history affects the response to new disturbances (Fong and Glynn 2000), with varying disturbance types and disturbance histories creating distinct and dissimilar signals in coral population structure. An acute disturbance caused by a severe storm is likely to destroy small and delicate corals, but will leave behind larger and more robust colonies (Massel and Done 1993, Rogers 1993); for branching corals, negative skewing of 
the population structure can result from the stimulatory effects of rising temperature on coral calcification (Edmunds 2005). Bak and Meesters (1999) used empirical data from both Curaçao and from Florida to suggest that a similar pattern (i.e., negative skewing) could result from the effects of deteriorating conditions on mortality patterns and recruitment (see also Lirman and Miller 2003). In contrast, positive skewing of the population structure of $M$. annularis under adverse conditions, as reported here, and previously described for Jamaica (Hughes and Tanner 2000), might reflect the effects of chronic mortality caused by disease, physiological stress, or algal overgrowth in reducing colony sizes through partial mortality and fission. Given the differing responses of coral population structure to disturbances, and the likelihood that coral populations will be affected simultaneously by events favoring both positive and negative skewing, an important research goal must be to understand how the demographic traits of coral populations interact with abiotic and biotic conditions to shape the population structure.

Regardless of the proximal causes, skewing of coral size structure has important implications. In particular, positive skewing has important implications for sexual reproduction, because coral fecundity is related positively to colony size (Jackson 1977, Hall and Hughes 1996), and sexual maturity is typically attained at a finite size (Soong 1991, Szmant 1991), with a potentially interactive effect of age (Kojis and Quinn 1985). Thus, a reduction in mean colony size will lower the populationlevel fecundity, and a positive skewing of the size structure may result in the majority of colonies belonging to a sexually immature size class. In the case of $M$. annularis, sexual maturity is achieved at $\sim 100 \mathrm{~cm}^{2}$ (Szmant 1991), and therefore by 2003, 70\% of the colonies on the study reef were probably functionally sterile (i.e., they were in size class I). In contrast, in 1988, $41 \%$ of the colonies were in size classes $\left(>50 \mathrm{~cm}^{2}\right)$ that included sexually mature individuals, and $7 \%$ were in the most fecund category (i.e., $>250 \mathrm{~cm}^{2}$; cf. $3 \%$ in 2003). Although it is unknown to what extent $M$. annularis populations are self-replenishing (sensu Black et al. 1991, Cowen et al. 2000), and therefore to what extent local populations are affected by local reproductive success, reduction in population-level fecundity will probably depress recruitment rates at some spatial scale, thereby creating a potential positive feedback loop on rates of population decline.

While the present analyses provide insights into the demographic processes causing a population of Montastraea annularis to decline, it provides little information on the proximal events determining the success of colonies. Some of these events are unambiguous, for example, the destruction caused by Hurricane Hugo in 1989 (Edmunds and Witman 1991, Rogers et al. 1991), while other conspicuous events, like the bleaching episode of 1987 (Roberts 1987, Glynn 1993), turned out to have surprisingly minor effects (Edmunds 2002).
Infrequent destructive events have played important roles on the reefs of St. John, as they have elsewhere (Karlson and Hurd 1993, Rogers 1993), but many of the recent phenomena affecting the study reef appear to be chronic events causing partial or complete mortality, or impaired growth. For example, over the years we have seen examples of $M$. annularis colonies that had been recently killed (i.e., the skeletons were stark white), possibly as a result of Plague Type II Disease (Sutherland et al. 2004), which has been killing colonies of $M$. annularis on the nearby Tektite Reef (Miller et al. 2003). Additionally, we often have found macroalgae, mostly Dictyota spp. and Halimeda spp., competing with, and growing over, $M$. annularis in interactions that can contribute to the death of coral tissue (Lirman 2001, McCook et al. 2001). Together with adverse abiotic conditions on the study reef, including warming seawater temperatures (Edmunds 2004) and turbid water, there is clearly a plethora of phenomena contributing to declining coral populations, yet it is impossible to determine the relative importance of each of these factors. For decades, ecological investigations of coral reefs have been influenced strongly by the goal of understanding the roles of major disturbances in community organization (Connell 1978, Karlson and Hurd 1993, Rogers 1993), most recently focusing on large-scale bleaching episodes (Fitt et al. 2001, Buddemeier et al. 2004). Now there is an urgent need for demographic studies designed to elucidate the effects of chronic, cumulative, and potentially subtle disturbances on coral populations in order to understand how reefs will change in the coming centuries.

\section{ACKNOWLedgments}

Over the years, this research has been funded from multiple sources, but the most consistent support has come from California State University, Northridge, and the Virgin Islands National Park. The demographic analysis of the long-term data described here was supported by grants from the Sea Grant Program of the University of Puerto Rico (\#R-101-2-02) and the National Science Foundation (DEB 0343570). We thank R. Boulon and C. Rogers for supporting our research in St. John for nearly two decades and the Virgin Islands Ecological Resource Station for hosting our visits. P. J. Edmunds particularly thanks his graduate students for assisting with fieldwork, S. Prosterman for providing scuba facilities, and V. Powell for on-site logistical support. Comments from an anonymous reviewer improved an earlier draft of this paper. This is contribution number 130 of the CSUN Marine Biology Program.

\section{Literature Cited}

Andres, N. G., and N. L. Rodenhouse. 1993. Resilience of corals to hurricanes: a simulation model. Coral Reefs 12:167-175.

Aronson, R. B., and W. F. Precht. 2001a. Evolutionary paleoecology of Caribbean coral reefs. Pages 171-233 in W. D. Allmon and D. J. Bottjer, editors. Evolutionary paleoecology: the ecological context of macroevolutionary change. Columbia University Press, New York, New York, USA.

Aronson, R. B., and W. F. Precht. 2001b. White band disease and the changing face of Caribbean coral reefs. Hydrobiologia 460:25-38. 
Babcock, R. C. 1991. Comparative demography of three species of scleractinian corals using age- and size-dependent classifications. Ecological Monographs 61:225-244.

Bak, R. P. M., and M. S. Engel. 1979. Distribution, abundance and survival of juvenile hermatypic corals (Scleractinia) and the importance of life history strategies in the parent community. Marine Biology 54:341-352.

Bak, R. P. M., and E. H. Meesters. 1999. Population structure as a response of coral communities to global change. American Zoologist 39:56-65.

Barnes, D. J. 1973. Growth in colonial scleractinians. Bulletin of Marine Sciences 23:280-298.

Bellwood, D. R., T. P. Hughes, C. Folke, and M. Nystrom. 2004. Confronting the coral reef crisis. Nature 429:827-833.

Berkelman, R., G. De'ath, S. Kininmonth, and W. J. Skirving. 2004. A comparison of the 1998 and 2002 coral bleaching events on the Great Barrier Reef: spatial correlation, patterns, and predictions. Coral Reefs 23:74-83.

Black, K. P., P. J. Moran, and L. S. Hammond. 1991. Numerical models show coral reefs can be self-seeding. Marine Ecology Progress Series 74:1-11.

Brown, B. E. 1997. Adaptation of reef corals to physical environmental stress. Advances in Marine Biology 31:221-299.

Buddemeier, R. W., J. A. Kleypas, and R. B. Aronson. 2004. Coral reefs and global climate change. Pew Center on Global Climate Change Report, Pew Center on Global Climate Change, Arlington, Virginia, USA.

Bythell, J. C., E. H. Gladfelter, and M. Bythell. 1993. Chronic and catastrophic natural mortality of three common Caribbean reef corals. Coral Reefs 12:143-152.

Bythell, J. C., Z. M. Hillis-Starr, and C. S. Rogers. 2000. Local variability but landscape stability in coral reef communities following repeated hurricane impacts. Marine Ecology Progress Series 204:93-100.

Caley, M. J., M. H. Carr, M. A. Hixon, T. P. Hughes, G. P. Jones, and B. A. Menge. 1996. Recruitment and the local dynamics of open marine populations. Annual Review of Ecology and Systematics 27:477-500.

Caswell, H. 2001. Matrix population models. Sinauer, Sunderland, Massachusetts, USA.

Collette, B. B., and S. A. Earle. 1972. Results of the Tektite program: ecology of coral reef fishes. Bulletin of the Natural History Museum of Los Angeles County 14.

Connell, J. H. 1973. Population ecology of reef-building corals. Pages 205-245 in O. A. Jones and R. Endean, editors. Biology and geology of coral reefs. Volume 2. Academic Press, New York, New York, USA.

Connell, J. H. 1978. Diversity in tropical rain forests and coral reefs. Science 199:1302-1310.

Connell, J. H. 1997. Disturbance and recovery of coral assemblages. Proceedings of the Eighth International Coral Reef Congress, Panama, 1:9-22.

Cowen, R. K., M. M. L. Kamazima, S. Sponaugle, C. B. Paris, and D. B. Olson. 2000. Connectivity of marine populations: open or closed. Science 287:857-859.

Done, T. J. 1987. Simulation of the effects of Acanthaster planci on the population structure of massive corals in the genus Porites: evidence of population resilience? Coral Reefs 6:7590.

Done, T. J. 1988. Simulation of recovery of pre-disturbance size structure in populations of Porites spp. damaged by the crown of thorns starfish Acanthaster planci. Marine Biology 100:51-61.

Done, T. J. 1992. Phase shifts in coral reef communities and their ecological significance. Hydrobiologia 247:121-132.

Done, T. J. 1999. Coral community adaptability to environmental changes at the scales of regions, reefs and reef zones. American Zoologist 39:66-79.

Dunstan, P. K., and C. R. Johnson. 1998. Spatio-temporal variation in coral recruitment at different scales on Heron Reef, southern Great Barrier Reef. Coral Reefs 17:71-81.
Dustan, P., and J. C. Halas. 1987. Changes in the reef-coral community of Carysfort Reef, Key Largo, Florida: 1974 to 1982. Coral Reefs 6:91-106.

Ebert, T. A. 1999. Plant and animal populations. Academic Press, San Diego, California, USA.

Edmunds, P. J. 2000. Patterns in the distribution of juvenile corals and coral reef community structure in St. John, U.S. Virgin Islands. Marine Ecology Progress Series 202:113-124.

Edmunds, P. J. 2002. Long-term dynamics of coral reefs in St. John, U.S. Virgin Islands. Coral Reefs 21:357-367.

Edmunds, P. J. 2004. Juvenile coral population dynamics track rising seawater temperature on a Caribbean reef. Marine Ecology Progress Series 269:111-119.

Edmunds, P. J. 2005. The effect of sub-lethal increases in temperature on the growth and population trajectories of three scleractinian corals on the southern Great Barrier Reef. Oecologia 146:350-364.

Edmunds, P. J., and J. F. Bruno. 1996. The importance of sampling scale in ecology: kilometer-wide variation in coral reef communities. Marine Ecology Progress Series 143:165-171.

Edmunds, P. J., and J. D. Witman. 1991. Effect of Hurricane Hugo on the primary framework of a reef along the south shore of St. John, U.S. Virgin Islands. Marine Ecology Progress Series 78:201-204.

Fairbanks, R. G. 1989. A 17000-year glacio-eustatic sea level record: influence of glacial melting rates on the Younger Dryas event and deep-ocean circulation. Nature 342:637-642.

Fitt, W. K., B. E. Brown, M. E. Warner, and R. P. Dunne. 2001. Coral bleaching: interpretation of thermal limits and thermal thresholds in tropical corals. Coral Reefs 20:51-65.

Fong, P., and P. W. Glynn. 1998. A dynamic size-structure population model: does disturbance control size structure of a population of the massive coral Gardinoseris planulata in the Eastern Pacific? Marine Biology 130:663-674.

Fong, P., and P. W. Glynn. 2000. A regional model to predict coral population dynamics in response to El Niño-southern oscillations. Ecological Applications 10:842-854.

Gaines, S., and J. Roughgarden. 1985. Larval settlement rate: a leading determinant of structure in an ecological community of the marine intertidal zone. Proceedings of the National Academy of Sciences (USA) 82:3707-3711.

Gardner, T. A., I. M. Cote, J. A. Gill, A. Grant, and A. R. Watkinson. 2003. Long-term, region-wide declines in Caribbean corals. Science 301:958-960.

Gladfelter, W. B. 1982. White-band disease in Acropora palmata: implications for the structure and growth of shallow water reefs. Bulletin of Marine Sciences 32:639-643.

Glynn, P. W. 1993. Coral reef bleaching: ecological perspectives. Coral Reefs 12:1-17.

Goreau, T. F. 1959. The ecology of Jamaican reefs. I. Species composition and zonation. Ecology 40:67-90.

Gosselin, L. A., and P.-Y. Qian. 1997. Juvenile mortality in benthic marine invertebrates. Marine Ecology Progress Series 146:265-282.

Hall, V. R., and T. P. Hughes. 1996. Reproductive strategies of modular organisms: comparative studies of reef-building corals. Ecology 77:950-963.

Hoegh-Guldberg, O. 1999. Climate change, coral bleaching and the future of the world's coral reefs. Marine and Freshwater Research 50:839-866.

Hudson, H. 1981. Growth rates in Montastraea annularis: a record of environmental change in Key Largo Coral Reef Marine Sanctuary, Florida. Bulletin of Marine Science 31: $444-459$.

Hughes, T. P. 1984. Population dynamics based on individual size rather than age: a general model with a reef coral example. American Naturalist 123:778-795.

Hughes, T. P. 1992. Monitoring of coral reefs: a bandwagon? Reef Encounters 11:9-12. 
Hughes, T. P. 1994. Catastrophes, phase shifts, and large-scale degradation of a Caribbean coral reef. Science 265:15471551.

Hughes, T. P. 1996. Demographic approaches to community dynamics: a coral reef example. Ecology 77:2256-2260.

Hughes, T. P., A. H. Baird, E. A. Dinsdale, N. A. Moltschaniwskyj, M. S. Pratchett, J. E. Tanner, and B. L. Willis. 1999. Patterns of recruitment and abundance of corals along the Great Barrier Reef. Nature 397:59-63.

Hughes, T. P., A. H. Baird, E. A. Dinsdale, N. A. Moltschaniwskyj, M. S. Pratchett, J. E. Tanner, and B. L. Willis. 2000. Supply-side ecology works both ways: the link between benthic adults, fecundity, and larval recruits. Ecology 81:2241-2249.

Hughes, T. P., et al. 2003. Climate change, human impacts, and the resilience of coral reefs. Science 301:929-933.

Hughes, T. P., and J. B. C. Jackson. 1985. Population dynamics and life histories of foliaceous corals. Ecological Monographs 55:141-166.

Hughes, T. P., and J. E. Tanner. 2000. Recruitment failure, life histories, and long-term decline of Caribbean corals. Ecology $81: 2250-2226$.

Idjadi, J. A., S. C. Lee, J. F. Bruno, W. F. Precht, L. AllenRequa, and P. J. Edmunds. 2006. Rapid phase-shift reversal on a Jamaican coral reef. Coral Reefs 25:209-211.

Jackson, J. B. C. 1977. Competition on marine hard substrata: the adaptive significance of solitary and colonial strategies. American Naturalist 980:743-767.

Jackson, J. B. C. 1992. Pleistocene perspectives on coral reef community structure. American Zoologist 32:719-731.

Jackson, J. B. C. 2001. What was natural in the coastal oceans? Proceedings of the National Academy of Sciences (USA) 98: $5411-5418$

Jackson, J. B. C., et al. 2001. Historical overfishing and the recent collapse of coastal ecosystems. Science 293:629-737.

Johnson, K. G., A. F. Budd, and T. A. Stemann. 1995. Extinction selectivity and ecology of neogene Caribbean reef corals. Paleobiology 21:52-73.

Karlson, R. H., and L. E. Hurd. 1993. Disturbance, coral reef communities, and changing ecological paradigms. Coral Reefs 12:117-125.

Kelley, D. 1994. The evolutionary ecology of mast seeding. Trends in Ecology and Evolution 9:465-470.

Koenig, W. D., and J. M. H. Knops. 2005. The mystery of masting in trees. American Scientist 93:340-347.

Kojis, B. L., and N. J. Quinn. 1985. Puberty size in Goniastrea favulus: age or size limited? Proceedings of the Fifth International Coral Reef Congress, Tahiti 4:289-293.

Knowlton, N. 1992. Thresholds and multiple stable states in coral reef community dynamics. American Zoologist 32:674 682.

Knowlton, N. 2001. The future of coral reefs. Proceedings of the National Academy of Sciences (USA) 98:5419-5425.

Knowlton, N. 2004. Multiple "stable" states and the conservation of marine ecosystems. Progress in Oceanography 60: 387-396.

Knowlton, N., J. L. Mate, H. M. Guzman, and R. Rowan. 1997. Direct evidence for reproductive isolation among the three species of the Montastraea annularis complex in Central America (Panama and Honduras). Marine Biology 127:705711

Lasker, H. R., and J. A. Sanchez. 2002. Astogeny and allometry of modular organisms. Pages 207-253 in K. G. Adiyodi and R. G. Adiyodi, editors. Reproductive biology of invertebrates. Volume XI: Progress in asexual reproduction. John Wiley and Sons, Chichester, UK.

Lee, C. C., E. L. Lee, and J. S. Bunt. 1975. Distribution of biomass in a coral reef transect. Natural History Museum of Los Angeles County Science Bulletin 20:69-103.

Levitan, D. R., H. Fukami, J. Jara, D. Kline, T. M. McGovern, K. E. McGhee, C. A. Swanson, and N. Knowlton. 2004.
Mechanisms of reproductive isolation among sympatric broadcast-spawning corals of the Montastraea annularis species complex. Evolution 58:308-323.

Lewis, J. B. 2004. Has random sampling been neglected in coral reef faunal surveys? Coral Reefs 23:192-194.

Lirman, D. 2001. Competition between macroalgae and corals: effects of herbivore exclusion and increased algal biomass on coral survivorship and growth. Coral Reefs 19:392-399.

Lirman, D., and M. W. Miller. 2003. Modeling and monitoring tools to assess recovery status and convergence rates between restored and undisturbed coral reef habitats. Restoration Ecology 11:448-456.

Massel, S. R., and T. J. Done. 1993. Effects of cyclone waves on massive coral assemblages on the Great Barrier Reef: meteorology, hydrodynamics and demography. Coral Reefs 12:153-166.

McClanahan, T. R. 2002. The near future of coral reefs. Environmental Conservation 29:460-483.

McCook, L. J., J. Jompa, and G. Diaz-Pulido. 2001. Competition between corals and algae on coral reefs: a review of evidence and mechanisms. Coral Reefs 19:400 425.

McPeek, M., and B. L. Peckarsky. 1998. Life histories and the strengths of species interactions: combining mortality, growth, and fecundity effects. Ecology 79:867-879.

Meesters, E. H., M. Hilterman, E. Kardinaal, M. Keetman, M. deVries, and R. P. M. Bak. 2001. Colony size-frequency distributions on scleractinian coral populations: spatial and interspecific variation. Marine Ecology Progress Series 209: 43-54.

Mesolella, K. J. 1967. Zonation of uplifted Pleistocenec coral reefs on Barbados, West Indies. Science 156:638-640.

Miller, J., R. Waara, and C. Rogers. 2003. Monitoring the coral disease Plague Type II, on coral reefs in St. John, U.S. Virgin Islands. Revista de Biología Tropical 51:47-55.

Mittelbach, G. G., C. F. Steiner, S. M. Scheiner, K. L. Gross, H. L. Reynolds, R. B. Waide, M. R. Willig, S. I. Dodson, and L. Gough. 2001. What is the observed relationship between species richness and productivity? Ecology 82:2381-2396.

Pandolfi, J. M., et al. 2003. Long-term decline of coral reef ecosystems. Science 301:955-957.

Precht, W. F., and R. B. Aronson. 2004. Climate flickers and range shifts of reef corals. Frontiers in Ecology and the Environment 2:307-314.

Raimondi, P. T., and A. N. C. Morse. 2000. The consequences of complex larval behavior in a coral. Ecology 81:3193-3211.

Roberts, L. 1987. Coral bleaching threatens Atlantic reefs. Science 238:1228-1229.

Rogers, C. S. 1993. Hurricanes and coral reefs: the intermediate disturbance hypothesis revisited. Coral Reefs 12:127-137.

Rogers, C. S., and J. Beets. 2001. Degradation of marine ecosystems and decline of fishery resources in marine protected areas in the U.S. Virgin Islands. Environmental Conservation 28:312-322.

Rogers, C. S., H. C. Fitz, M. Gilnack, J. Beets, and J. Hardin. 1984. Scleractinian coral recruitment patterns at Salt River Submarine Canyon, St. Croix, U.S. Virgin Islands. Coral Reefs 3:69-76.

Rogers, C. S., V. Garrison, and R. Grober-Dunsmore. 1997. A fishy story about hurricanes and herbivory: seven years of research on a reef in St. John, U.S. Virgin Islands. Proceedings of the Eighth International Coral Reef Congress, Panama 1:555-560.

Rogers, C. S., L. N. McLain, and C. R. Tobias. 1991. Effects of Hurricane Hugo (1989) on a reef in St. John, USVI. Marine Ecology Progress Series 78:189-199.

Rogers, C. S., and J. Miller. 2006. Permanent 'phase shifts' or reversible declines in coral cover? Lack of recovery of two coral reefs in St. John, U.S. Virgin Islands. Marine Ecology Progress Series 306:103-114. 
Rogers, C. S., and R. Teytaud. 1988. Marine and terrestrial ecosystems of the Virgin Islands National Park and Biosphere Reserve. Biosphere Reserve Report 29:1-112.

Romme, W. H., M. G. Turner, G. A. Tuskan, and R. A. Reed. 2005. Establishment, persistence, and growth of aspen (Populus tremuloides) seedlings in Yellowstone National Park. Ecology 86:404-418.

Sheppard, C. R. C. 1982. Coral populations on reef slopes and their major controls. Marine Ecology Progress Series 7:83115.

Smith, A. H., C. S. Rogers, and C. Bouchon. 1997. Of western Atlantic reefs in the Lesser Antilles. Proceedings of the Eighth International Coral Reef Congress, Panama 1:351-356.

Smith, L. D., M. Devlin, D. Harnes, and J. P. Gilmour. 2005. A demographic approach to monitoring the health of coral reefs. Marine Pollution Bulletin 51:399-407.

Sokal, R. R., and F. J. Rohlf. 1995. Biometry. W. H. Freeman, New York, New York, USA.

Soong, K. 1991. Sexual reproduction patterns of shallow-water reef corals in Panama. Bulletin of Marine Sciences 49:832-846.

Stoddart, D. R. 1969. Ecology and morphology of recent coral reefs. Biological Reviews 44:433-498.
Sutherland, K. P., J. W. Porter, and C. Torres. 2004. Disease and immunity in Caribbean and Indo-Pacific zooxanthellate corals. Marine Ecology Progress Series 266:273-302.

Szmant, A. M. 1991. Sexual reproduction by the Caribbean reef corals Montastrea annularis and $M$. cavernosa. Marine Ecology Progress Series 74:13-25.

Szmant, A. M., E. Weil, M. W. Miller, and D. E. Colon. 1997. Hybridization within the species complex of the scleractinian coral Montastraea annularis. Marine Biology 129:561-572.

Warner, R. R., and P. L. Chesson. 1985. Coextistence mediated by recruitment fluctuations: a field guide to the storage effect. American Naturalist 125:769-787.

Weil, E., and N. Knowlton. 1994. A multi-character analysis of the Caribbean coral Montastrea annularis (Ellis and Solander, 1786) and its two sibling species, M. faveolata (Ellis and Solander, 1786) and $M$. franksi (Gregory, 1895). Bulletin of Marine Science 55:151-175.

Woodley, J. D., et al. 1981. Hurricane Allen's impact on Jamaican coral reefs. Science 214:749-755.

Woodruff, D. S. 2001. Declines of biomes and biotas and the future of evolution. Proceedings of the National Academy of Sciences (USA) 98:5471-5476.

\section{APPENDIX A}

Map showing the location of the study site $\left(18^{\circ} 18.910^{\prime} \mathrm{N}, 64^{\circ} 43.501^{\prime} \mathrm{W}\right)$ on the south coast of St. John, U.S. Virgin Islands (Ecological Archives M077-001-A1).

\section{APPENDIX B}

Autocorrelation plots displaying the results of statistical tests for independence among contiguous quadrats, 10 of which are positioned along each of the three transect lines (Transects 1-3) forming the core of the long-term study site off Yawzi Point, St. John, U.S. Virgin Islands (Ecological Archives M077-001-A2).

\section{APPENDIX C}

Transition matrices and elasticity analyses for a population of Montastraea annularis at Yawzi Point (9-m depth) for 1988-1993, 1993-1998, and 1998-2003 at St. John, U.S. Virgin Islands (Ecological Archives M077-001-A3).

\section{APPENDIX D}

Population growth rate $(\lambda)$ and damping ratios $(\rho)$ for Montastraea annularis at $9-\mathrm{m}$ depth in St. John, U.S. Virgin Islands (Ecological Archives M077-001-A4). 